\title{
Categorized wetland preference and life forms of the vascular plants in the Korean Peninsula
}

Yeonsook Choung ${ }^{1 *}$ (D), Byeong Mee Min ${ }^{2}$, Kyu Song Lee ${ }^{3}$, Kang-Hyun Cho ${ }^{4}$, Kwang Yeong Joo ${ }^{5}$, Jin-Oh Hyun ${ }^{6}$, Hye Ryun $\mathrm{Na}^{6}$, Hyun Kyung $\mathrm{Oh}^{7}$, Gi-Heum Nam${ }^{7}$, Jin-Seok Kim7, Soyeon Cho ${ }^{1}$, Jongsung Lee', Sangyeop Jung ${ }^{1}$ and Jaeyeon Lee ${ }^{1}$

\begin{abstract}
Background: In 2020, a categorized list of wetland preferences, major habitats, and life forms of 4145 vascular plant taxa occurring in the Korean Peninsula was published by the National Institute of Biological Resources. We analyzed the list and explored the distribution patterns of the five categorized groups according to wetland preference, along with the information on the major habitats and the life forms of the plants belonging to those categories.

Results: Out of 4145 taxa, we found that 729 wetland plant taxa (18\%) occur in Korea: 401 obligate wetland plants and 328 facultative wetland plants. Among the 729 wetland taxa, the majority (73\%) was hygrophytes and the remaining $27 \%$ was aquatic macrophytes. Furthermore, almost all of the wetland taxa are herbs; so, woody plants are only $4.7 \%$. The 16 carnivorous taxa distributed in Korea were characterized as obligate wetland plants.
\end{abstract}

Conclusions: We expect the categorized information would promote understanding of the characteristics of the plant species and would be an important source for understanding, conservation, and restoration of wetland ecosystems.

Keywords: Growth form, Habitat, Nutrition mode, Seasonality, Wetland indicator status

\footnotetext{
* Correspondence: yschoung@kangwon.ac.kr

'Department of Biological Sciences, Kangwon National University,

Chuncheon 24341, Republic of Korea

Full list of author information is available at the end of the article
}

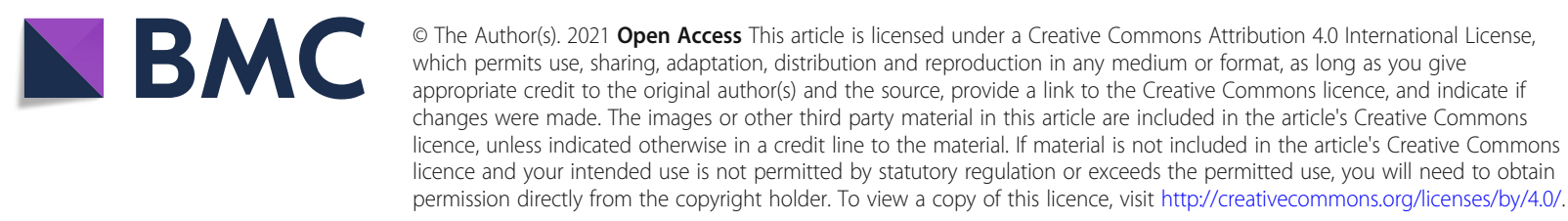




\section{Main text}

In 2020, Choung et al. published a book on wetland preference and life forms of vascular plants occurring in the Korean Peninsula. The book contains information on 4145 native and naturalized vascular plant taxa based on the National Species List of Korea provided by the National Institute of Biological Resources (2019). The core content categorizes all vascular plants into five groups according to their wetland preferences. Additionally, it includes categorized details of the major habitats and life forms, such as growth form, seasonality, and nutritional mode. Categorizing plant species distributed over a broad spectrum into a small number of groups is truly useful because such information is necessary for understanding, conservation, and restoration of wetland ecosystems.

Information provided by most of the authors of this book was previously available (Choung et al. 2012). However, in the new book (Choung et al. 2020), the base list of the species was changed from Lee (1996) to the National Institute of Biological Resources (2019), and the definition of the wetlands was made more specific. Furthermore, the number of reference sources (books, websites, and publications) has increased in these few years. Based on those backgrounds, information on all the species was evaluated in the new book. Typically, the definition of wetland varies depending upon the countries, institutions, and researchers. Previously, the definition was based on the Ramsar Convention (1971), i.e., wetlands are areas of marsh, fen, peatland, or water, whether natural or artificial, permanent, or temporary, with water that is static or flowing, fresh, brackish, or salty, including areas of marine water, the depth of which at low tide does not exceed $6 \mathrm{~m}$. In the new book, wetland was defined as an area where the soil or bottom substrate of the habitat is either underwater or wet regardless of the size whether large or small, respectively. By defining it specific, small spaces where only a few individuals can inhabit, such as small puddles or small damp places in the forest, were considered as wetlands. However, places with high air humidity, such as lower mountain slopes or valley forests, were not included as wetlands.

The purpose of this article is to report the distribution patterns of vascular plants in Korea categorized according to their wetland preference and to provide information on the major habitats and life forms such as growth form, seasonality, and nutritional mode of the plants belonging to five categories.

\section{Categorizing wetland preference of vascular plants}

Wetland preference of plants was categorized into five groups according to their frequency of occurrence in the wetlands. For classification, the U.S. Fish and Wildlife Service (1997) was modified and adopted. The categorization was not the result of quantitative research, but a product of collaborative discussion with the frequency values as a reference by a group of specialists with several decades of field experience.

- Obligate wetland plants (OBW) occur almost always in wetlands under natural conditions (estimated frequency of occurrence $>98 \%$ in wetlands)

- Facultative wetland plants (FACW) usually occur in wetlands but occasionally found in non-wetlands too (estimated 71-98\% in wetlands)

- Facultative plants (FAC) likely to occur equally in both wetlands and non-wetlands (estimated 31-70\% in wetlands)

- Facultative upland plants (FACU) occasionally occur in wetlands, but usually occur in non-wetlands (estimated 3-30\% in wetlands)

- Obligate upland plants (OBU) almost never occur in wetlands under natural conditions (estimated $<3 \%$ in wetlands)

Based on this classification, 401 taxa (10\%) and 328 taxa (8\%) among 4,145 taxa were found to fall in the category of $\mathrm{OBW}$ and FACW, respectively (Fig. 1). A total of 729 wetland plant taxa (18\%) are distributed in Korea, considering OBW and FACW as wetland plants. This is a significant difference, compared to the wetland plants previously at $12 \%$ (OBW and FACW 6\% each) (Choung et al. 2015). It mainly resulted from the re-establishment of the spatial scopes of the wetlands. The FAC with the widest distribution range for moisture includes 430 taxa (10\%). The OBU with 2,511 taxa becomes the largest group comprising $61 \%$ of the total taxa. When FACU with 475 taxa (11\%) was included, the upland plants reached $72 \%$.

The only information that can be compared with the above classification is the U.S. Army Corps of Engineers (2016). Of the 8080 taxa across the USA, OBW and FACW were 23 and $21 \%$, respectively, resulting in total $44 \%$. Since the USA has vast areas of lakes, swamps, and stream channels, there is a possibility that the proportion of wetland plants is higher in the USA than that in Korea (Hack 1968). However, this difference may mainly be due to the specific criteria of evaluation of the wetland plants. On comparing the common species of the two 


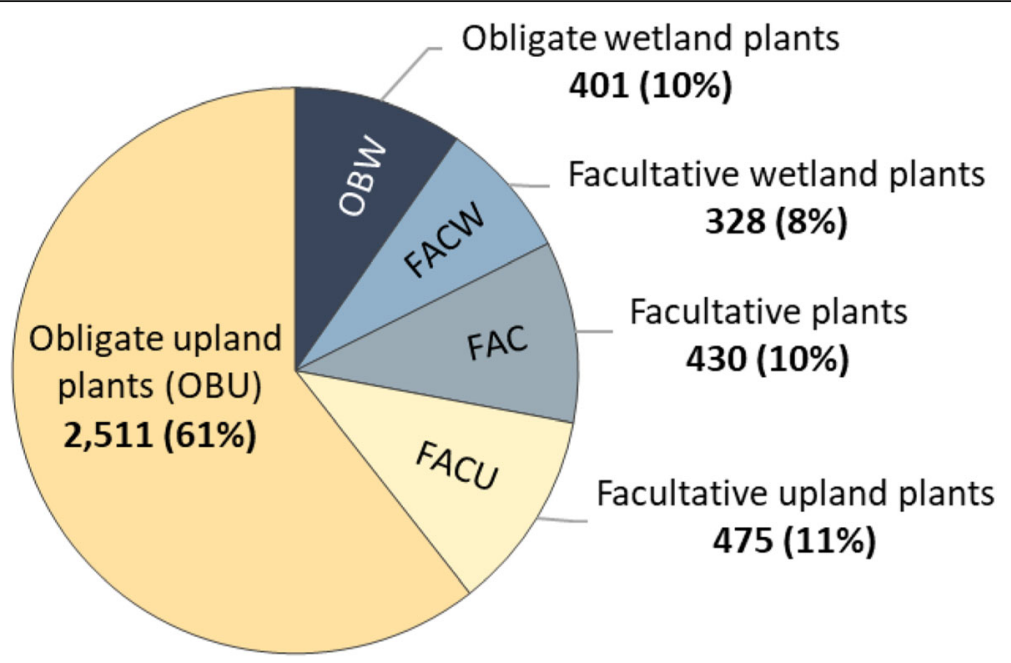

Fig. 1 Wetland preference of the vascular plants in the Korean Peninsula assessed using frequency of occurrence in wetlands

countries, most of the plants distributed in habitats with high air humidity were evaluated as wetland plants in the U.S. Army Corps of Engineers (2016).

Among the wetland plants, the distributions of aquatic macrophytes and hygrophytes were analyzed. The aquatic macrophytes refer to plants that have adapted to environment such as fresh water and seawater, and grow inside water, or near water with a water level higher than the surface. The hygrophytes are plants that have adapted to a place which is usually saturated with water up to the surface, but having seasonal water level fluctuations. Among the 729 taxa of the wetland plants, most (73\%) are hygrophytes and the remaining $27 \%$ are aquatic macrophytes (Fig. 2). Also, there are four types of aquatic macrophytes of which the emergent plants are the most common. To note, all the aquatic macrophytes (199 taxa) and a portion of the hygrophytes (202 taxa) belong to OBW, while FACWs comprises all the hygrophytes.

\section{Categorizing major habitats of vascular plants}

Out of the total vascular taxa, $79 \%$ inhabits in terrestrial environments, such as meadow, and shrublands, and forests as their major habitats, while the rest $21 \%$ inhabits in wetlands (Fig. 3). Meadows and shrublands represent mountain slope, open slope and area, thicket, scrub, and coast where most of the light-demanding plants thrive. On the other hand, forest is a particular area which houses plants with some degree of shade-tolerance.

OBWs are distributed in both aquatic environments and wet meadows in similar proportions (Table 1).

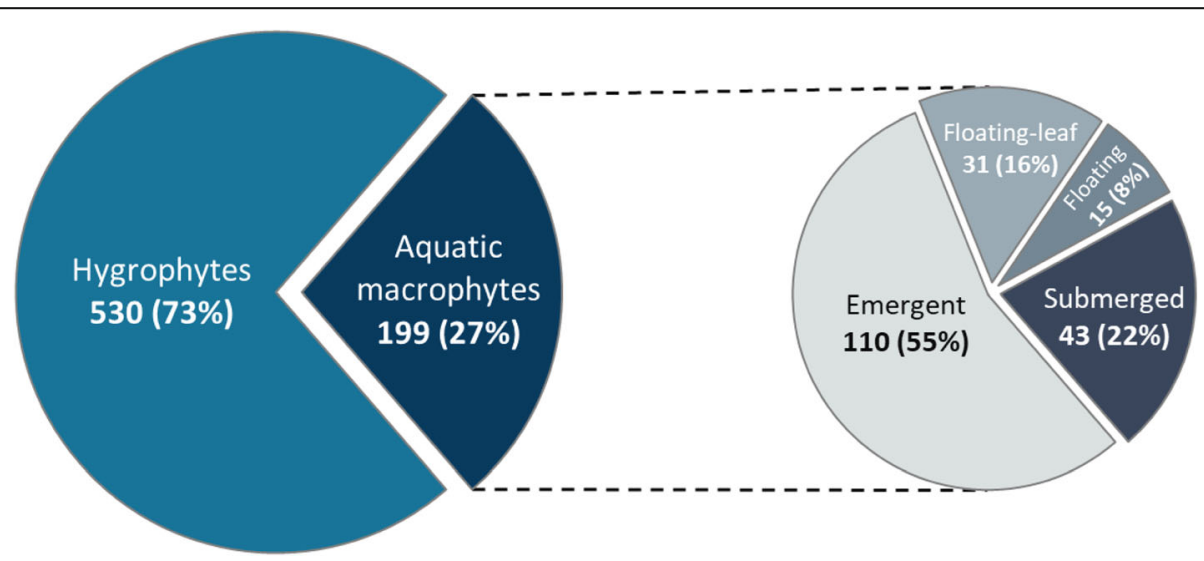

Fig. 2 Distribution of hygrophytes and aquatic macrophytes in the Korean peninsula (left) and four types of aquatic macrophytes according to their adaptation morphology (right). Number of taxa and percentage are shown within parentheses 


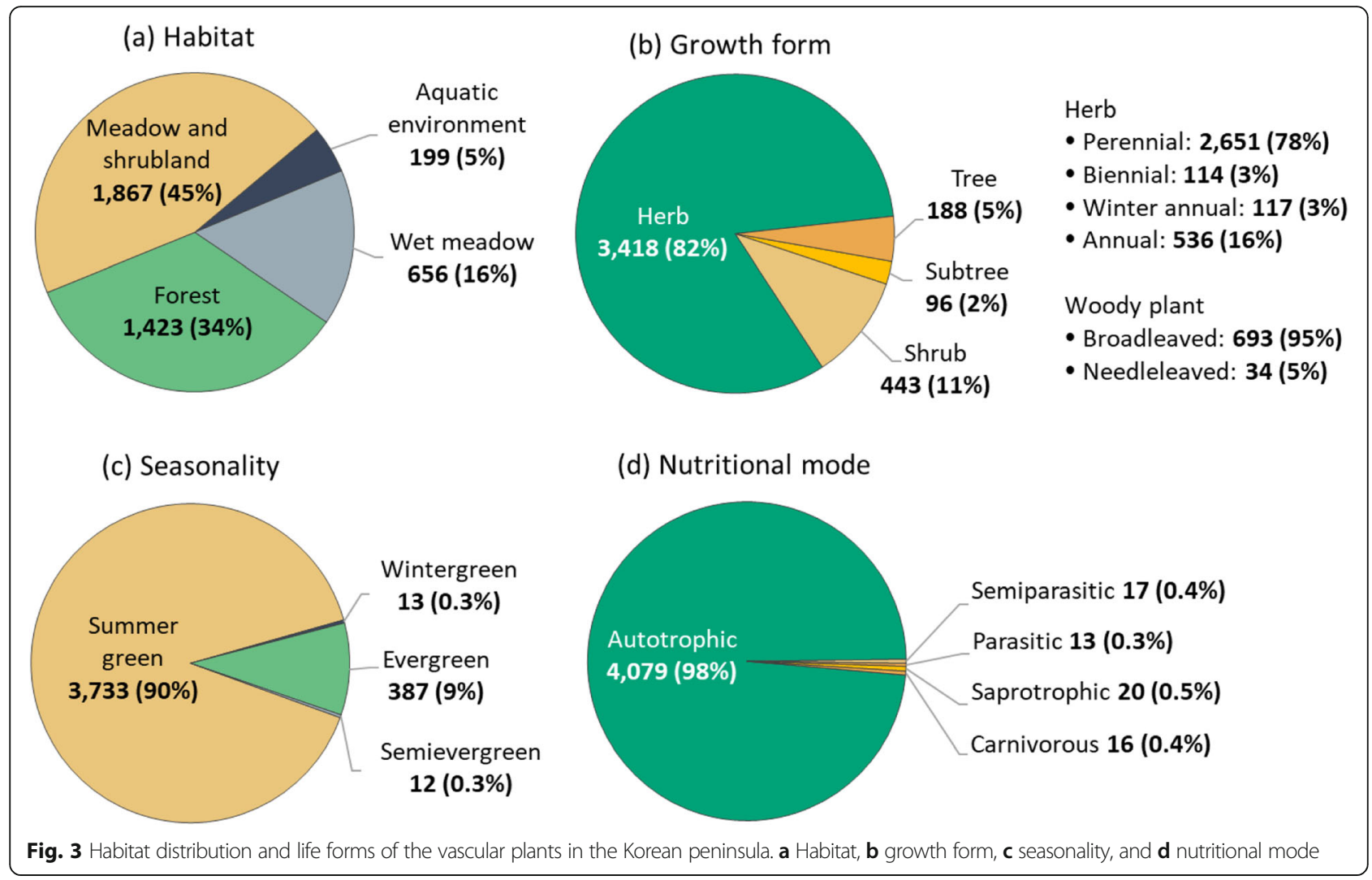

The aquatic environment is an area located in a body of water, and while the wet meadow is an area such as a moor, the riparian, and littoral zone, which are saturated with water throughout much of the year. Among the OBWs, 1 taxon (Glyceria lithuanica) is distributed in the forests. FACW does not appear in aquatic environment, and $92 \%$ occurs in wet meadows, such as watersides, ditches, and rice fields. The remaining $8 \%$ taxa are distributed in forests which developed from wet meadows. The FACs thrive under the widest distribution of moisture conditions-from wet meadows and damp forests to shrublands and roadsides. The FACUs are mostly found in forests, shrublands, and open areas, but infrequently they appear in wetlands too. By contrast, the OBUs are mainly distributed in forests, shrubs, and grasslands and almost never inhabit in wetlands under natural conditions.

\section{Categorizing growth forms of vascular plants}

Among growth forms of the total taxa, herbs accounted for $82 \%$ (3418 taxa). Of the herbs, $78 \%$ are perennial and $16 \%$ are annual (Fig. 3). Shrubs and trees account for 443 taxa (11\%) and 188 taxa (5\%), respectively. Among the woody plants (shrubs, subtrees, and trees), 95\% are broadleaved and the rest are needleleaved. Almost all of OBWs (99\%) are herbs (Table 1). There are no OBWs among the trees or subtrees, only 4 shrub taxa, namely Andromeda polifolia, Chamaedaphne calyculata, Vaccinium microcarpum, and $V$. oxycoccus are OBWs. The trees and subtrees of 16 taxa such as Salix and Populus belong to FACW.

\section{Categorizing seasonality of vascular plants}

Among the total taxa, summer green plants are the most distributed (90\%), while evergreen trees are only 387 taxa (9\%) (Fig. 3). The wintergreen plant is a plant with green leaves in the winter and lose leaves in the summer. The wintergreen contains 13 taxa, e.g., Botrychium atrovirens and Diplazium mettenianum. They are all ferns and have been found in Jeju Island. Only 9 taxa (1.2\%) of the OBWs and FACWs are evergreen plants (Table 1). Generally, most of the evergreen and semievergreen plants are OBUs. The semievergreen plant is a plant that is incompletely evergreen. Some leaves fall in autumn, whereas the rest near the surface stay evergreen in winter.

\section{Categorizing nutritional mode of vascular plants}

Autotrophic plants account for $98 \%$ of the total taxa. On the other hand, semiparasitic (e.g., Viscum 
Table 1 Habitat distribution and life forms of the vascular plants in the Korean Peninsula according to wetland preference categories

\begin{tabular}{|c|c|c|c|c|c|}
\hline \multirow[t]{2}{*}{ Properties } & \multicolumn{5}{|c|}{ Wetland preference } \\
\hline & $\begin{array}{l}\text { Obligate wetland } \\
\text { plants (OBW) }\end{array}$ & $\begin{array}{l}\text { Facultative wetland } \\
\text { plants (FACW) }\end{array}$ & $\begin{array}{l}\text { Facultative } \\
\text { plants (FAC) }\end{array}$ & $\begin{array}{l}\text { Facultative upland } \\
\text { plants (FACU) }\end{array}$ & $\begin{array}{l}\text { Obligate upland } \\
\text { plants (OBU) }\end{array}$ \\
\hline \multicolumn{6}{|l|}{ Habitat } \\
\hline Aquatic environment & $199(49.6)$ & & & & \\
\hline Wet meadow & $201(50.1)$ & $300(91.5)$ & $155(36.0)$ & & \\
\hline Forest & $1(0.2)$ & $28(8.5)$ & $129(30.0)$ & $139(29.3)$ & $1125(44.8)$ \\
\hline Meadow and shrubland & & & $146(34.0)$ & $336(70.7)$ & $1386(55.2)$ \\
\hline Total & $401(100)$ & $328(100)$ & $430(100)$ & $475(100)$ & $2511(100)$ \\
\hline \multicolumn{6}{|l|}{ Growth form } \\
\hline Herb & $397(99.0)$ & $298(90.9)$ & $398(92.6)$ & $422(88.8)$ & $1903(75.8)$ \\
\hline Shrub & $4(1.0)$ & $14(4.3)$ & $22(5.1)$ & $37(7.8)$ & $366(14.6)$ \\
\hline Subtree & & $4(1.2)$ & $4(0.9)$ & $6(1.3)$ & $82(3.3)$ \\
\hline Tree & & $12(3.7)$ & $6(1.4)$ & $10(2.1)$ & $160(6.4)$ \\
\hline Total & $401(100)$ & $328(100)$ & $430(100)$ & $475(100)$ & $2511(100)$ \\
\hline \multicolumn{6}{|l|}{ Seasonality } \\
\hline Summer green & $397(99.0)$ & $323(98.5)$ & $404(94.0)$ & $439(92.4)$ & $2170(86.4)$ \\
\hline Wintergreen & & & $2(0.5)$ & & $11(0.4)$ \\
\hline Evergreen & $4(1.0)$ & $5(1.5)$ & $24(5.6)$ & $36(7.6)$ & $318(12.7)$ \\
\hline Semievergreen & & & & & $12(0.5)$ \\
\hline Total & $401(100)$ & $328(100)$ & $430(100)$ & $475(100)$ & $2511(100)$ \\
\hline \multicolumn{6}{|l|}{ Nutritional mode } \\
\hline Autotrophic & $385(96.0)$ & $328(100)$ & $428(99.5)$ & 473 (99.6) & 2465 (98.2) \\
\hline Semiparasitic & & & $1(0.2)$ & $1(0.2)$ & $15(0.6)$ \\
\hline Parasitic & & & $1(0.2)$ & $1(0.2)$ & $11(0.4)$ \\
\hline Saprotrophic & & & & & $20(0.8)$ \\
\hline Carnivorous & $16(4.0)$ & & & & \\
\hline Total & $401(100)$ & $328(100)$ & $430(100)$ & $475(100)$ & $2511(100)$ \\
\hline
\end{tabular}

Values are number of taxa and percentage (in parentheses) within each wetland preference

coloratum and Melampyrum setaceum), parasitic (e.g., Cuscuta japonica and Orobanche coerulescens), and saprotrophic plants (e.g., Cymbidium macrorhizon and Monotropa uniflora) are only 50 taxa (Fig. 3). These plants obtain energy from other plant sources, most of which are OBUs (Table 1). Apart from these, 16 taxa are carnivorous plants (e.g., Drosera rotundifolia and Utricularia tenuicaulis) which take inorganic nutrients from other organisms. All of them belong to OBWs (Table 1).

\section{Conclusions}

To conclude, we analyzed the list of categorized vascular plant species according to wetland preferences. Such analysis gives deeper insight into the characteristics of plant species distributed in the Korean Peninsula. In particular, we expect the categorized information to serve as the indicator for health assessment of aquatic ecosystems, including rivers and lakes, thereby providing better understanding, conservation, and restoration of wetland ecosystems.

\section{Abbreviations}

OBW: Obligate wetland plant; FACW: Facultative wetland plant; FAC: Facultative plant; FACU: Facultative upland plant; OBU: Obligate upland plant

\section{Acknowledgements}

Not applicable.

Authors' contributions

CY wrote the manuscript; MBM, LKS, CKH, JKY, HJO, NHR, OHK, NGH, and KJS revised the manuscript; and $C S, L J, J S$, and $L J$ analyzed the database. The author(s) read and approved the final manuscript.

Funding

Not applicable. 


\section{Availability of data and materials}

The categorized list of all vascular plants is open-accessed at the National Institute of Biological Resources.

\section{Declarations}

\section{Ethics approval and consent to participate}

Not applicable.

\section{Consent for publication}

Not applicable.

\section{Competing interests}

The authors declare that they have no competing interests.

\section{Author details}

'Department of Biological Sciences, Kangwon National University,

Chuncheon 24341, Republic of Korea. ${ }^{2}$ Department of Science Education, Dankook University, Yongin 16890, Republic of Korea. ${ }^{3}$ Department of Biology, Gangneung-Wonju National University, Gangneung 26403, Republic of Korea. ${ }^{4}$ Department of Biological Sciences, Inha University, Incheon 22212, Republic of Korea. ${ }^{5}$ National Institute of Ecology, Seocheon 33657, Republic of Korea. ${ }^{6}$ Northeastern Asia Biodiversity Institute, Hanam 12982, Republic of Korea. ${ }^{7}$ Plant Resources Department, National Institute of Biological Resources, Incheon 22689, Republic of Korea.

Received: 24 January 2021 Accepted: 28 February 2021

Published online: 12 March 2021

\section{References}

Choung Y, Lee WT, Cho KH, Joo KY, Min BM, Hyun JO, Lee KS. Categorizing vascular plant species occurring in wetland ecosystems of the Korean Peninsula. Seoul: Center for Aquatic Ecosystem Restoration; 2012.

Choung Y, Lee WT, Cho KH, Joo KY, Min BM, Hyun JO, Lee KS, Lee K, Seo A. Status of wetland vascular plant species in Korea. J Ecol Environ. 2015; 38(4):541-4.

Choung Y, Min BM, Lee KS, Cho KH, Joo KY, Hyun JO, Na HR, Oh HK, Nam GH, Kim JS. Wetland preference and life form of the vascular plants in the Korean Peninsula. Incheon: National Institute of Biological Resources; 2020.

Hack JT. Landforms of the United States. Denver: U.S. Geological Survey; 1968. Lee WT. Lineamenta Florae Koreae. Seoul: Academy Book; 1996.

National Institute of Biological Resources. The list of National species of Korea. Incheon: National Institute of Biological Resources; 2019.

Ramsar Convention. Convention on wetlands of international importance especially as waterfowl habitat. Gland: Ramsar Convention on Wetlands; 1971

U.S. Army Corps of Engineers. National wetland plant list (ver. 3.3). Washington D. C.: U.S. Army Corps of Engineers; 2016.

U.S. Fish and Wildlife Service. National list of vascular plant species that occur in wetlands. Washington D.C.: U.S. Fish and Wildlife Service; 1997.

\section{Publisher's Note}

Springer Nature remains neutral with regard to jurisdictional claims in published maps and institutional affiliations. 